\title{
Prevalence of Malnutrition Risk in Patients with Oncological Pathology who Attend their First Nutritional Medical Control
}

\author{
Buso C, Perri N, Maltagliatti D*, Albarello G, Rosales C, Sanchotena V, Santoro ML, Costa F, Devoto L, Filgueira N, \\ Aillon D, Arias C, Flaks D and Carrasco M
}

Staff Doctor, Maria Curie Municipal Oncology Hospital, Argentina

Submission: May 13, 2021; Published: June 3, 2021

*Corresponding author: Maltagliatti D, Breast Pathology Service, Maria Curie Municipal Oncology Hospital, CABA, Argentina

\section{Abstract}

Nutritional alterations are frequent in patients with active oncological pathology. The prevalence of malnutrition in this group is $15-20 \%$ at the time of diagnosis and $80-90 \%$ in patients with advanced disease.

The different tumors show nutritional risks according to their location, their degree of involvement of the digestive tract and the type of cancer treatment established.

It is a descriptive study of the prevalence of global risk of malnutrition. We included 898 patients with oncological pathology who attended to Nutrition and Diabetes Department of Maria Curie Municipal Oncology Hospital of Buenos Aires between June 2019 and June 2020 . The objective was to analyze the prevalence of global risk of malnutrition through MUST in patients who attend their first nutritional medical control.

An analysis of the score was carried out ina group of patients with high global risk of malnutrition, observing that $27.79 \%$ obtained the highest evaluation of score $4.44 \%$ of the patients had breast cancer, followed by cervix, ovary and uterus cancer with $13 \%$ and then cancer of the mouth, oral/tongue in $12 \%$.

Malnutrition is a frequent complication in cancer patients and it is significantly associated with an increasement in morbidity/mortality according to some bibliography. The nutritional assessment of patient with cancer should begin at the time of diagnosis in order to initiate nutritional intervention early, reducing associated complications and improving the patient's quality of life.

Keywords: Malnutrition; Cancer; MUST; Diabetes mellitus

Abbreviations: DM: Diabetes Mellitus; HbA1c: Hemoglobin A1c; ESPEN European Society for Clinical Nutrition and Metabolism; MUST: Malnutrition Universal Screening Tool; IARC: International Agency for Research on Cancer

\section{Introduction}

Cancer is a pathology with the greatest health implications, not only because of its frequency but also because of its high morbidity and mortality, which leads to a great deterioration in the quality of life of the patient and his family [1]. According to data published by the International Agency for Research on Cancer (IARC) in 2018, Argentina presented an incidence rate of 212 cases of cancer per 100,000 inhabitants (considering both sexes and all tumors except skin carcinoma not melanoma). This determines a medium-high incidence of cancer (range 177 to 245.6 per 100,000 inhabitants), placing Argentina in seventh place over the Latin American countries. This estimate corresponds to more than 125,000 new cases of cancer in both sexes per year [2].

Nutritional alterations are frequent in the population with active oncological pathology. Malnutrition is a frequent problem in cancer patients, with a prevalence of $15-20 \%$ at the time of diagnosis and $80-90 \%$ in patients with advanced disease [3]. The different tumors present predictable nutritional risks depending on their location, the degree of involvement of the digestive tract and the type of cancer treatment established. At the time of cancer diagnosis, more than $50 \%$ of patients have some type of 
nutritional problem and around 75\% lose weight. Malnutrition is frequently associated with pancreatic and stomach cancer and is less frequently related to breast, hematological and sarcomas neoplasms, according to different population series [3]. For this reason, the nutritional assessment of the cancer patient should begin at the time of diagnosis and be repeated at each visit to carry out an early intervention, before the general condition is severely compromised [4].

The objectives of nutritional treatment are to prevent and treat malnutrition, reinforce the effects of antitumor treatment by reducing its adverse effects, and improve quality of life [4]. Many patients in the first nutritional consultation present risk elements that can be documented in a simple and effective way with the use of validated tools such as NSR 2002 or the MUST. Nutritional screening methods must be valid, reliable, reproducible and easy to be apply. There is no universally accepted method for cancer patients, although some of them have been validated in this type of patient (MUST, NRS-2002, OST, MST). The European Society for Clinical Nutrition and Metabolism (ESPEN) recommends using the Nutritional Risk Screening (NRS-2002) in hospitalized patients and the Malnutrition Universal Screening Tool (MUST) in outpatients [5].

\section{Objectives}

Analyze the prevalence of global risk of malnutrition through MUST in outpatients who attended their first nutritional consultation, by referral from Hospital Admission or from referral services such as Clinical Oncology, Maxillofacial Surgery or Stomatology or Breast Pathology, among others. Differentiate type, tumor location and comorbidities (Diabetes Mellitus and / or Metabolic Syndrome - ATPIII Criteria) in order to determine the appropriate nutritional therapy and intervention.

\section{Methods}

Retrospective, observational study of the prevalence of global risk of malnutrition, which included 898 patients with oncological pathology who attended the outpatient Nutrition and Diabetes clinics of the Marie Curie Municipal Oncology Hospital in the City of Buenos Aires between June 2019 and June 2020. The selection of subjects has been carried out by means of a continuous tabulation, in cancer patients who attend the nutritional consultation for the first time, without any distinction regarding stage or antitumor treatments carried out and who meet the established inclusion criteria (greater than 18 years, tumor diagnosis documented by pathological anatomy and first nutritional consultation). The MUST screening tool was used with three possible outcomes, Habitual Risk (value 0), Intermediate Risk (value 1), High Risk (values greater than 2), The variables analyzed were age, sex, type and location of cancer, comorbidities, nutritional screening by MUST, BMI, involuntary weight loss and assessment of the effect of the acute disease (Defined as Anemia (Hematocrit less than $30 \%$ and / or Hemoglobin less of $10 \mathrm{~g}$-dl and / or fasting glucose greater than or equal to $180 \mathrm{mg} \%$ and / or glycosylated hemoglobin A1c greater than 9\%). The overall risk of malnutrition was determined after considering all the variables.

Moreover, the presence of Diabetes Mellitus documented according to American Diabetes Association/Argentine Diabetes Association 2019 criteria (fasting blood glucose equal to or greater than $126 \mathrm{mg} \%$ on two occasions or any documented blood glucose greater than $200 \mathrm{mg} \%$ or a PTOG $75 \mathrm{~g}$ of glucose with a value of the two hours equal to or greater than $200 \mathrm{mg} \%$ - A1c was not considered as a diagnostic analyte since the use of A1c HPLC cannot be established in all patients in the series). A descriptive analysis of the variables was carried out to know the distribution of the sample. Continuous variables were expressed as mean \pm standard deviation or as median (minimum maximum). To determine the normality of the variables, the KolmogorovSmirnov test was performed. Qualitative variables were expressed as absolute number and percentage. Parametric / non-parametric tests were performed to determine the potential association between the study variables. The database was made in an Excel file and the statistical treatment was carried out using the Stata 13 software.

This study had the approval of the Teaching and Research Committee of the Municipal Hospital of Oncology - María Curie, and according to the resolution of the MNSAL 1480-2011, the realization of Informed Consent has not been proposed, since only data is used in the research or non-linkable samples or information of public knowledge where it is preserved and it is not possible to establish the identity of the people.

\section{Results}

The sample was made up of 898 people, being $73.27 \%$ female $(\mathrm{n}=658)$ and $26.73 \%$ male $(\mathrm{n}=240)$. The mean age was 56.10 years (SD 10.40 years), with a median and mode of 57 and 54 years respectively, with the maximum value being 84 and the minimum 23 years. Nutritional screening by MUST of our population showed that $82.74 \%$ of the sample presents intermediate and high nutritional risk, and only 17.26\% low (Figure 1).

High values were obtained in the MUST score in 743 patients $(82.74 \%)$ of the population, 81 patients belonging to the intermediate risk group and 662 to the high risk population. When subdividing the high-risk population, 58.3\% corresponded to MUST 2 values, $13.89 \%$ to MUST 3 values and $27.79 \%$ to MUST 4 values (Figure 2). When evaluating the tumor type, 44\% (327 patients) presented breast cancer, followed by cervical, ovarian and uterine cancer with 13\% (97 patients) and then mouth, oral / tongue cancer in $12 \%$ (86 patients) (Figure 3).

Regarding the comorbidities present at the time of consultation, it was observed that $30.4 \%$ of the population had diabetes and $8.91 \%$ had metabolic syndrome by ATPIII criteria (Figure 4). 


\section{NUTRITIONAL RISK ACCORDING TO MUST}

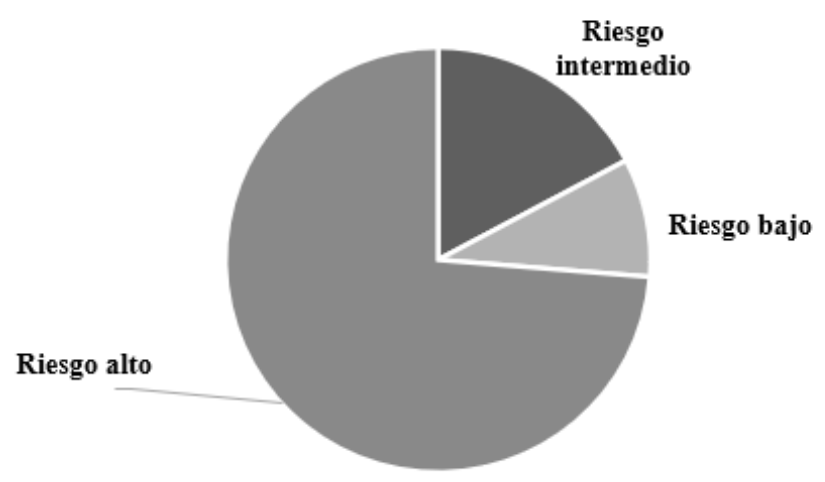

Figure 1: Nutritional risk according to MUST.

\section{HIGH GLOBAL RISK OF MALNUTRITION ACCORDING TO MUST}

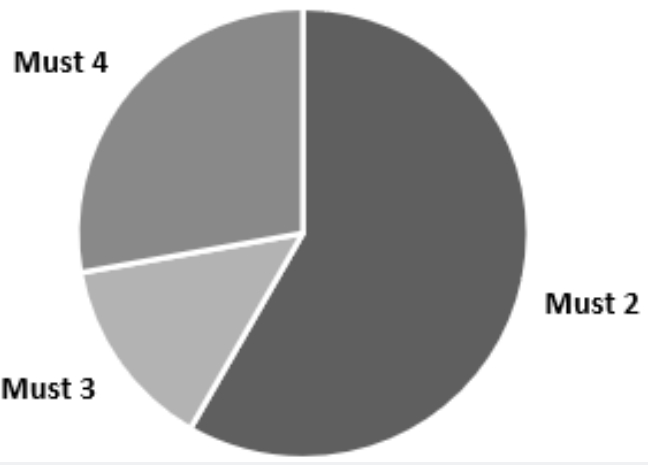

Figure 2: High global risk of malnutrition according to MUST.

Tumor Type

\begin{tabular}{|l|}
\hline Thyroid \\
Muscle Sarcoma \\
Kidney \\
Intestine \\
Lung \\
Prostate \\
Pancreas \\
Nose \\
Melanoma \\
Breast \\
Lymphoma \\
Larynx \\
Esophagus \\
Cervix, ovary, uterus \\
Mouth, oral, tongue
\end{tabular}

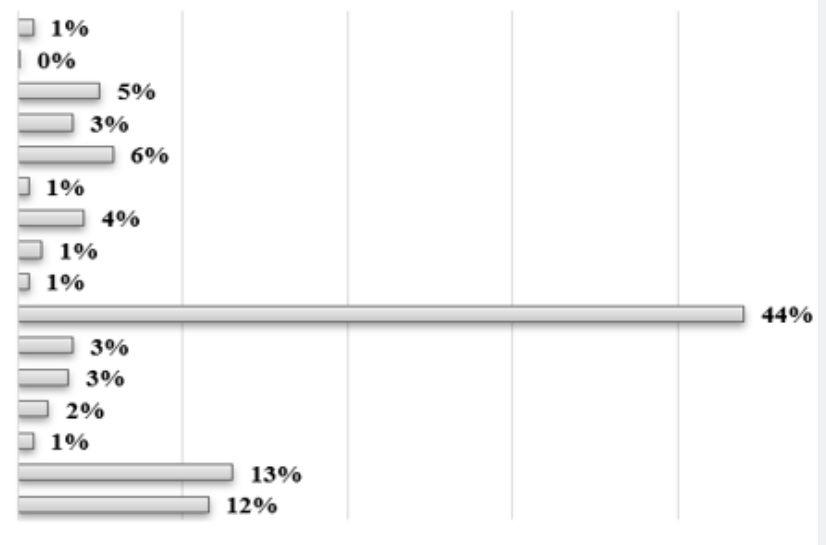

Figure 3: Association with comorbidities. 


\section{Current Research in Diabetes \& Obesity Journal}

\section{Discussion}

Malnutrition has a high prevalence in cancer patients, increasing this with the progression of the tumor. The incidence ranges from $15 \%$ at the onset of the disease to more than $80 \%$ in advanced stages, which is correlated with the data obtained in our sample where $82.74 \%$ presented malnutrition rates [6]. There is a wide frequency variability depending on the neoplastic lineage. The most prevalent tumor type in this series presented was breast carcinoma, in contrast to data obtained from the international bibliography where gastric and pancreatic cancer are associated with malnutrition rates higher than 80\% [6]. Among the neoplasms that have been related to diabetes mellitus (DM), breast cancer is undoubtedly the most linked in our sample. DM can increase the risk of death by $49 \%$ in women with breast cancer when compared to women without carbohydrate metabolism disorders. In addition, it has been confirmed that in people with glycosylated hemoglobin A1c (HbA1c) values $\geq 7 \%$, the recurrence of this neoplasm may increase. The fundamental problem is the fact that in more than $30 \%$ of people with breast cancer the diagnosis of type 2 DM is delayed or not made in a timely manner [7].

In the present study it was evidenced that $30.4 \%$ of the total sample had DM. Of the population with breast cancer, $39 \%$ had this comorbidity. This suggests the possibility of conducting new studies to analyze the association between these findings [8].

\section{Limitations of the Study}

In the present survey, it should be taken into account that the patients attended in Nutrition from several referral sources, from the same Admission at the primary moment of their admission to the hospital, as derived from different services such as Maxillofacial Surgery, Stomatology or Oncology Clinic. It is noteworthy that one of the hospital services that routinely refers patients for nutritional consultation is Breast Pathology, which may explain the number of patients received from that unit. On the other hand, the MUST assessment was performed but no reference was made to the tumor stage at the time of our first consultation, since many were not yet staged by the Oncologist and the objective from Nutrition was to highlight in "real life" how the patients arrived at the query.

\section{Conclusions}

Malnutrition is a prevalent diagnosis in the cancer population and there is great difficulty in maintaining and / or improving their nutritional status. Malnutrition is a frequent complication and is significantly associated with an increase in morbidity / mortality according to the available literature. This situation has a great impact on functional capacity, with an increase in complications, an increase in the rate of infections and a decrease in tolerance to cancer treatment, which leads to a decrease in the quality of life of the patient.

The nutritional assessment of the cancer patient should begin at the time of diagnosis and be repeated at each visit to initiate nutritional intervention early, before the general condition is severely compromised and the chances of recovering the situation of normality are scarce. The objectives of nutritional treatment are to prevent and treat malnutrition, reinforce the effects of antitumor treatment by reducing its adverse effects, and improve quality of life. Therefore, early detection of malnutrition or the risk of suffering from it is the first step in nutritional assessment.

At hospital intervention programs, the use of a valid and reliable nutritional screening method is essential to know the initial condition of the patient and to establish early adequate nutritional support for each problem. A high prevalence of type 2 DM concomitant with some neoplasms has been observed in this series, as has been reported in the available worldwide bibliography. Due to this, and given the impact of this entity on the patient's prognosis, we believe it is very important to consider the systematic search for DM and timely treatment to support the success of cancer treatment. Taking into account the observed high nutritional risk (MUST) figures in this series of first visit patients, with a predominance of tumors that a priori, according to the bibliography, could have a low risk of malnutrition, we consider that the early Nutritional Assessment should be included at the time of hospital admission. Situation that would allow an early approach, adequate support, preparing the patient for the different moments of cancer treatment, including Palliative Care.

\section{References}

1. Garcia-Luna P, Parejo Campos J, Pereira Cunill JL (2006) Causas e impacto clínico de la desnutrición y caquexia en el paciente oncológico. Nutr Hosp 21(3): 10-16.

2. (2018) International Cancer Research Agency (IARC). StatisticsIncidence. INC. Argentine Health Ministry.

3. Fernández López, MT, Sáenz Fernández A, Saspradamt D, Alonso Urrutia S, Bardasco Alonso ML, et al. (2013) Desnutrición en el paciente con cáncer: una experiencia de cuatro años. Nutr Hosp 28(2): 372-811.

4. Bozzetti F, Arends J, Lundholm K (2009) ESPEN Guidelines on Parenteral Nutrition: Non-surgical oncology. Clin Nutr 28(4): 445-454.

5. Arends J, Bodoky G, Bozzetti F, K Fearon, M Muscaritoli, et al. (2006) ESPEN Guidelines on Enteral Nutrition: Non-surgical oncology. Clin Nutr 25(2): 245-255

6. Sánchez-Sánchez E, López-Aliaga I, Muñoz Alférez MJ (2018) Cribado nutricional en pacientes oncológicos: análisis de tres métodos. Nutr Hosp 35(6): 1324-1330.

7. (2011) Malnutrition Action Group (MAG) Comité Permanent British Association for Parenteral and Enteral Nutrition (BAPEN). Explanatory manual. MUST.

8. Gárciga-Cardoso F, Licea-Puig M (2012) Relación entre la diabetes mellitus y el cáncer. Revista Peruana de Epidemiología. 16(2): 69-75. 


\begin{tabular}{l} 
Your next submission with Juniper Publishers \\
will reach you the below assets \\
- Quality Editorial service \\
- Swift Peer Review \\
- Reprints availability \\
- E-prints Service \\
- Manuscript Podcast for convenient understanding \\
- Global attainment for your research \\
- Manuscript accessibility in different formats \\
- Unceasing customer service \\
Track the below URL for one-step submission \\
https://juniperpublishers.com/online-submission.php \\
\hline
\end{tabular}

